\title{
Parthenolide regulates DNMT1-mediated methylation of VDR promoter to relieve podocyte damage in mice with diabetic nephropathy
}

\author{
Xinbo YANG ${ }^{1}$, Yulei ZHANG ${ }^{2}$, Ni YANG ${ }^{1}$, Xiao YU ${ }^{1}$, Xin $\mathrm{GAO}^{1}$, Meiyun $\mathrm{ZHAO}^{3 *}$
}

\begin{abstract}
Current evidence showed that parthenolide (PN) has strong anti-inflammatory activity, but its effect on diabetic nephropathy (DN) is still unclear. In this research, high glucose (HG)-induced MPC5 cells were incubated with 5, 10 or $20 \mu \mathrm{M}$ PN, and we found that PN incubation improved HG-induced MPC5 cells viability and apoptosis, ROS level, LDH activity and the secretion of inflammatory factors (IL-6, TNF- $\alpha$ and IL-1 $\beta$ ), and inhibited the expression of DNMT1 protein, and promoted the expression of VDR, p-AKT, nephrin and podocin proteins. Lentivirus-mediated VDR overexpression vector (LV-VDR) transfection had the same effect, and LV-DNMT1 or si-VDR transfection or $100 \mathrm{nM}$ AKT inhibitor MK2206 incubation reversed the effect of PN on cell functions. Research on the mechanism found that PN reduced the level of VDR methylation by reducing the enrichment of DNTM1 in the VDR promoter region under high glucose condition. In vivo, C57BL/6 mice were injected with streptozotocin (STZ) intraperitoneally to construct a DN mouse model, and $5 \mathrm{mg} / \mathrm{kg}$ PN was administered intraperitoneally every other day. The results showed that PN treatment improved glomerular hypertrophy and renal fibrosis in STZ-induced mice. In general, PN regulated DNTM1-mediated VDR methylation, activated AKT, and alleviated DN.
\end{abstract}

Keywords: parthenolide; DNMT1; methylation; VDR; MPC cells; diabetic nephropathy.

Practical Application: Parthenolide (PN) was originally extracted from the shoots of plant Feverfew, and it is reported that PN has strong anti-inflammatory activity, but its effect on diabetic nephropathy (DN) is unclear. Herein, we find that PN treatment alleviates STZ-induced kidney injury in vivo and HG-induced MPC5 cells dysfunction in vitro. Mechanism investigation reveals that PN reduces the expression level of DNMT1 protein, inhibits DNMT1-mediated VDR methylation, promotes the expression level of VDR protein, and activates the AKT pathway, thereby alleviating DN.

\section{Introduction}

Diabetic nephropathy (DN) is a serious complication of diabetes. According to estimates by the World Health Organization, there are approximately 422 million diabetic patients in the world, of which more than $90 \%$ have type 2 diabetes (T2DM) (Cho et al., 2018; World Health Organization, 2015). As we all know, DN is the main cause of chronic kidney disease and endstage renal disease, and it is closely related to T2DM (Ritz et al., 1999; Wang et al., 2021). In China, there are approximately 114 million people with diabetes, which greatly harms public health(Zhen et al., 2020). The epigenetic modification of genes plays an important role in the development of DN, among which DNA methylation is the most common (Keating et al., 2017). Related research reported that DNA methylation could participate in the regulation of genes related to the functions of glomeruli and proximal tubular epithelial cells, including filtration, glucose and solute processing (Wanner \& Bechtel-Walz, 2017). DNA methylation is mediated by DNA methyltransferase, which inhibits gene expression by recruiting transcription repressors to the promoter region of genes and interfering with transcription factor binding (Jones, 2012).
According to reports, in the state of diabetes, the expression of DNA methyltransferase 1 (DNMT1) in podocytes in vivo and in vitro is significantly increased. In the in vitro diabetes model induced by high glucose (HG), 5-azacytidine treatment can significantly reduce the expression of DNMT1, and improve the reduction of podocyte slit diaphragm protein caused by hypermethylation (Zhang et al., 2017). At present, the treatment of type 2 diabetes with traditional Chinese medicine has become more and more common (Ahmad et al., 2020). Parthenolide (PN) was originally extracted from the shoots of plant Feverfew, and has strong anti-tumor, anti-inflammatory and antibacterial biological activities (Freund et al., 2020). A study claimed that $\mathrm{PN}$ as an inhibitor of nuclear factor kappa B (NF- $\mathrm{BB})$, after treating diabetic mice, it could reduce inflammation, alleviate glomerular hypertrophy, remodel the damaged insulin signal transduction pathway, and promote the expression of renal tubular cubicin protein and uptake of albumin (Hao et al., 2020). Moreover, it is reported that PN could regulate the expression and methylation level of tumor-related genes by inhibiting the 
activity of DNMT1 (Liu et al., 2009), but this mechanism of action has not been reported in $\mathrm{DN}$.

Vitamin D Receptor (VDR) is a member of the nuclear hormone receptor superfamily, which could regulate the transcription of target genes and mediate the genomic effects of vitamin D. VDR is expressed in many tissues involved in glucose metabolism, including pancreas, liver and kidneys (Palomer et al., 2008). A study showed that VDR is closely related to $\mathrm{DN}$ and insulin resistance, suggesting that the expression of VDR in the serum of DN patients is reduced, and increasing the level of VDR can alleviate proteinuria, renal fibrosis, kidney inflammation and prevent podocyte damage (Yang et al., 2018). According to a report, there is a significant correlation between the methylation level of the VDR gene promoter and the phenotype of tuberculosis patients, and the sequencing results show that the VDR gene of tuberculosis patients is in a state of hypermethylation (Jiang et al., 2017). A study examined the skin pigmentation and VDR promoter methylation levels of children with diabetes and their brothers and sisters, and found that the two may be related to diabetes (Ponsonby et al., 2009), but the effect of VDR methylation on DN has not been reported. A study reported that compared with the control group, the expression level of DNMT1 in kidney cells of human immunodeficiency virus (HIV) transgenic mice and HIV-infected podocytes is increased, and CpG methylation of the VDR promoter is increased, indicating that VDR transcription and translation is inhibited (Nirupama Chandel, \& Lan, 2015). A study reported that increased levels of VDR could up-regulate AKT signal transduction and reduce oxidative stress in renal tubular cells induced by high glucose (Zhu et al., 2019), simultaneously, increased levels of AKT phosphorylation could alleviate streptozotocin (STZ)-induced mice DN (Rai et al., 2019).

In this study, we investigated the effects of parthenolide from both in vivo and in vitro levels on STZ-induced DN of C57BL/6 mice and high glucose-induced MPC5 cell damage, and the corresponding mechanisms.

\section{Materials and methods}

\subsection{Cell culture and treatment}

The conditionally immortalized mouse podocytes (MPC5) were purchased from American Type Culture Collection (ATCC, Manassas, VA). The podocytes were maintained in DMEM medium containing $10 \%$ inactivated FBS (Gibco, Rockville, MD), $100 \mathrm{U} / \mathrm{mL}$ penicillin and $0.1 \mathrm{mg} / \mathrm{mL}$ streptomycin at $37^{\circ} \mathrm{C}$ in a humidified atmosphere with 5\% CO2. Normal control group cells were cultured in DMEM normal medium $(5.5 \mathrm{mmol} / \mathrm{L}$ glucose), high glucose (HG) group cells were cultured in DMEM high glucose medium ( $25 \mathrm{mmol} / \mathrm{L}$ glucose) and parthenolide treatment group cells were cultured in DMEM normal medium and added $10 \mu \mathrm{M}$ parthenolide. After the cells were cultured for 72 hours, the next step was performed.

\subsection{Retroviral construction infection and transfection}

Lentivirus-mediated VDR overexpression vector (LV-VDR) and LV-DNMT1, small interfering RNA against VDR (si-VDR) and si-DNMT1 and respective negative control vector or scramble were purchased from SinoBiological (Beijing, China) and transfected by using Sinofection ${ }^{\otimes}$ transfection reagent (SinoBiological) according to the manufacturer's instructions.

\subsection{Animal model}

30 male C57BL/6 mice aged 6-8 weeks were divided into three groups, including the control group, the DN group and the $\mathrm{DN}+\mathrm{PN}$ group, with 10 mice in each group. To induce $\mathrm{DN}$, mice were injected with $50 \mathrm{mg} / \mathrm{kg}$ streptozotocin (STZ) intraperitoneally continue 5 days, and the mice were fed with high-fat and high-sugar for 6 weeks. Two weeks after the injection, blood was collected by mandibular vein puncture with Bayer glucose meter (Bayer, Leverkusen, Germany) to measure blood glucose. The mice with fasting blood glucose $>12 \mathrm{mmol} / \mathrm{L}$ were successfully modeled. The control group was injected with citrate buffer, and the mice in the $\mathrm{DN}+\mathrm{PN}$ group were injected with $5 \mathrm{mg} / \mathrm{kg}$ parthenolide intraperitoneally every other day after modeling for 4 weeks. Then, the mice were sacrificed and serum and kidney tissues were collected. All programs were approved by the Xi'an Hospital of Traditional Chinese Medicine Animal Care and Use Committee and were carried out in accordance with the National Institutes of Health "Guidelines for the Care and Use of Laboratory Animals".

\subsection{Hematoxylin-Eosin (HE) and Masson staining}

The tissues were collected, HE and Masson staining were used to study the pathological changes of mouse kidney. The kidney was fixed in $4 \%$ paraformaldehyde solution for 48 hours, and then embedded in paraffin. The $5 \mu \mathrm{m}$-thick serial sections cut from the paraffin block were stained with HE and Masson tricolor solution. H-800 electron microscope (Hitachi, Tokyo, Japan) was used to examine ultrathin sections. The blue area in Masson staining represents fibrosis in kidney tissues.

\subsection{Cell viability}

The cell viability was determined with the 3-(4,5-dimethylthiazol2-yl)-2,5-diphenyltetrabromoazole (MTT) method according to the instructions. In short, MPC 5 cells with a density of $4 \times 10^{3}$ cells/ well were seeded in 96-well plates, and 5, 10, 15, 20, 25, 35 and $50 \mu \mathrm{M}$ parthenolide were respectively added and incubated for $72 \mathrm{~h}$. Then, $100 \mu \mathrm{L}$ of $5 \mathrm{mg} / \mathrm{mL}$ MTT solution (Solaibao, Beijing, China) was added to each well, and the cells were incubated at $37^{\circ} \mathrm{C}$ for 4 hours, the supernatant was discarded, and $150 \mu \mathrm{L}$ of dimethyl sulfoxide (DMSO) was added to dissolve the crystals for 10 minutes. The absorbance at $490 \mathrm{~nm}$ was used as the detection standard on a microplate reader (Boston Thermal Science, USA), and cell viability was expressed as a percentage.

\subsection{Methylation-specific PCR assay}

The PCR was carried out with HotStar Taq polymerase (Qiagen, Dusseldorf, Germany). The conditions were as follows: initial incubation at $95{ }^{\circ} \mathrm{C}$ for 4 minutes; 35 cycles of $95^{\circ} \mathrm{C}$ for $30 \mathrm{~s}, 74^{\circ} \mathrm{C}$ for $30 \mathrm{~s}, 72^{\circ} \mathrm{C}$ for $30 \mathrm{~s}$; PCR products were electrophoresed in $3 \%$ agarose gels and visualized by ultraviolet illumination. The sequence of VDR MSP primer were constructed 
by Sangon (Shanghai, China) and presented as follows: methylated primer: 5'-AGA TGC GTT TTT GTT TTT TGC-3' (forward) and 5'-CGA AAA AAC TTT CTA CCA ACG TC-3' (reverse); unmethylated primer: 5'-GGA GAT GTG TTT TTG TTT TTT GTG-3' (forward) and 5'-CCT CAA AAA AAC TTT CTA CCA ACA T-3' (reverse).

\subsection{Real-time quantitative PCR assay}

Isolation of RNA from cultured cells and tissues was performed with Trizol Reagent (Invitrogen, Carlsbad, CA, USA) following the manufacturer's instructions. The mRNA expression levels were determined by using real-time quantitative RT-PCR with a Bio-Rad iCycler system (Bio-Rad, Hercules, CA) in a $20 \mu \mathrm{L}$ reaction system. The reaction protocol was: pre-denaturation at $95^{\circ} \mathrm{C}$ for $3 \mathrm{~min} ; 95^{\circ} \mathrm{C}$ for $5 \mathrm{~s}, 60^{\circ} \mathrm{C}$ for $15 \mathrm{~s}$, and amplification rounds of 40 cycles at $40^{\circ} \mathrm{C}$ for $1 \mathrm{~min}$ per cycle. GAPDH was used as an internal reference. The results were represented as relative mRNA levels calculated by $2^{-\triangle \Delta C T}$ method. Primers were constructed by Sangon (Shanghai, China) and presented as follows: nephrin: 5'-GGC AGG ATC TGC AAG CTA CAT3' (forward) and 5'-CTC AGG GCC TTC AGG GT GAG-3' (reverse); podocin: 5'-GAT GCT TCC TGC GGA GAT AGA3' (forward) and 5'-TTC CTG TCC AGC AAA ATG TCA-3' (reverse); VDR: 5'- GCT AAG ATG ATA CCA GGA TTC AGA GAC-3' (forward) and 5'-AAG GAC TCA TTG GAG CGC AAC-3' (reverse) and GAPDH: 5'-CCT GGC CAA GGT CAT CCA TG-3' (forward) and 5'-GCA GGA GAC AAC CTG GTC CT-3' (reverse).

\subsection{Chromatin Immunoprecipitation (Ch-IP)}

Ch-IP assay was performed according to the manufacturers' instructions by using Magna Ch-IP HiSens Kit (Millipore, Boston, MA, USA). Chromatin samples were immunoprecipitated with antibodies against a negative control normal rabbit monoclonal IgG and DNMT1 antibodies (Abcam, Cambridge, UK). PCR amplification was performed in $20 \mu \mathrm{L}$ volumes for 30-35 cycles to determine the appropriate conditions for the PCR products of each region. Primer sequences were same as RT-qPCR.

\subsection{Western blot}

RIPA lysis buffer (Thermo Fisher Scientific, Waltham, MA, USA) were used to extract the proteins from cells or tissues and BCA protein assay kit (Thermo Fisher Scientific) was used to measure the total protein concentration. Briefly, $30 \mu \mathrm{g} / \mathrm{lane}$ protein from each sample was resolved by $10 \%$ SDS-PAGE at $70 \mathrm{~V}$ for $30 \mathrm{~min}$, followed by $120 \mathrm{~V}$ for $90 \mathrm{~min}$. Then, the protein bands were transferred to polyvinylidene difluoride (PVDF) membranes (Thermo Fisher Scientific) by using Power Blotter-semi-dry fast transfer system (Thermo Fisher Scientific) at $300 \mathrm{~mA}$ for $2 \mathrm{~h}$. And then membranes were blocked with 5\% nonfat milk overnight at $4{ }^{\circ} \mathrm{C}$, after that, membranes were incubated at room temperature for $2 \mathrm{~h}$ with the following primary antibodies: rabbit polyclonal anti-DNMT1 antibody (1:1000, ab19905), rabbit monoclonal anti-VDR antibody (1:1000, EPR4552), rabbit polyclonal anti-phospho T308 antibody (1:1000, ab8933), rabbit monoclonal anti- nephrin antibody (1:1000, ab216341), rabbit monoclonal anti- podocin antibody $(1: 2000, a b 181143)$ and rabbit polyclonal anti-GAPDH antibody (1:2500, ab9485), which were purchased from Abcam (Cambridge, UK). And then the membranes were incubated with horseradish peroxidase (HRP)conjugated goat anti-rabbit IgG (1:1000, \#7074, Cell Signaling Technology, Boston, MA, USA) at room temperature for $1 \mathrm{~h}$. Then, the protein bands were visualized with ECL detection reagents (Sigma, St. Louis, MO, USA) and analyzed with ImageJ software (National Institutes of Health, Bethesda, MA, USA).

\subsection{Enzyme-linked immunosorbent assay (ELISA) assay}

After the mice were sacrificed, the serum was collected. The levels of lactate mouse dehydrogenase (LDH), tumor necrosis factor (TNF)- $\alpha$, interleukin (IL)- 6 , and IL- $1 \beta$ in serum and MPC5 cells were determined with specific ELISA kits (BioTeke, Beijing, China) according to the manufacturer's protocol. The absorbance of each hole was determined at $450 \mathrm{~nm}$ by an Infinite M200 plate reader (Tecan, Austria).

\subsection{Detection of apoptosis by flow cytometry}

After transfection, the cells were collected and washed three times with cold phosphate-buffered saline (PBS), resuspended in binding buffer, and stained with $5 \mu \mathrm{L}$ of AnnexinV-FITC and $5 \mu \mathrm{L}$ of propidium iodide (PI) in the dark at $4{ }^{\circ} \mathrm{C}$ for $15 \mathrm{~min}$, then, the stained cells were analyzed by using a flow cytometer (Beckman Gallios, Fullerton, CA, USA).

\subsection{Measurement of ROS production}

A fluorescent probe dichloro-dihydro fluorescein diacetate (DCFH-DA) (Sigma, USA) was used to detect ROS levels intracellular. After different stimuli were introduced, cells were incubated with $50 \mu \mathrm{M}$ DCFH-DA at $37^{\circ} \mathrm{C}$ for $30 \mathrm{~min}$ in the dark. Then, the cells were washed twice with cold PBS. A fluorescence microscope (Konrad technologies, Germany) was used to obtain a fluorescence image of intracellular ROS and the average fluorescence intensity was analyzed with an image analysis system (ImageJ, National Institutes of Health).

\subsection{Statistical analysis}

In vitro experiments were repeated more than 3 times. Data were presented as mean \pm standard deviation (SD). pairwise comparison between groups using Student's t-test and comparison of multiple groups using analysis of variance (ANOVA) followed by SPSS 22.0. $P<0.05$ indicates the difference was statistically significant.

\section{Results}

\subsection{Effect of parthenolide on MPC5 cells damage induced by high glucose}

We explored the effect of PN at a concentration of 5-50 $\mu \mathrm{M}$ on cell viability and found that cell viability was significantly reduced after a concentration of $35 \mu \mathrm{M}$ and $50 \mu \mathrm{M}$ PN treatment (Figure 1A). Compared with the control group, we found that 
the MPC5 cells apoptosis, ROS level, LDH activity and secretion of cytokine IL-6, TNF- $\alpha$ and IL- $1 \beta$ were significantly increased (Figure 1B-H), while the mRNA and protein expression levels of nephrin, podocin and VDR were significantly reduced in HG treatment group (Figure 1I-O). Compared with the HG group, the different concentrations $(5 \mu \mathrm{M}, 10 \mu \mathrm{M}$, and $20 \mu \mathrm{M})$ of PN treatment significantly improved cell functionin in a dose-dependent manner.

\subsection{Parthenolide regulates DNMT1-mediated methylation of VDR promoter}

A study reported that in the state of diabetes, the expression of podocyte DNA methyltransferase 1 (DNMT1) in vivo and in vitro is significantly increased (Zhang et al., 2017), and parthenolide could regulate the methylation level of genes by inhibiting DNMT1 (Liu et al., 2009). And we also confirmed that
A
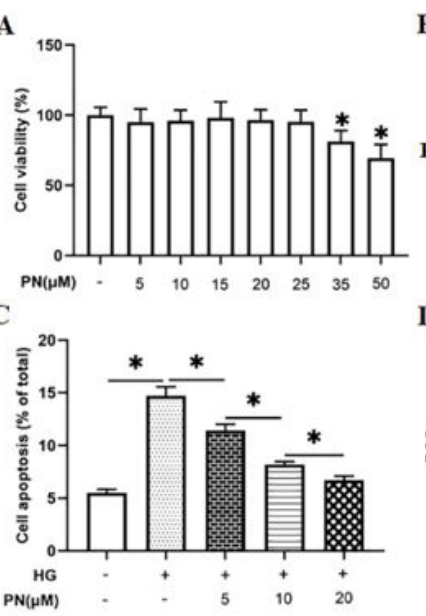

G

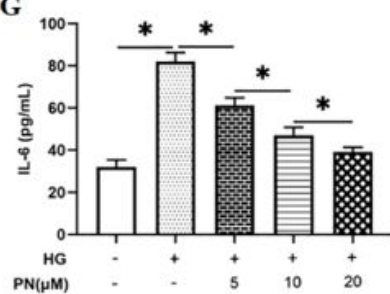

K
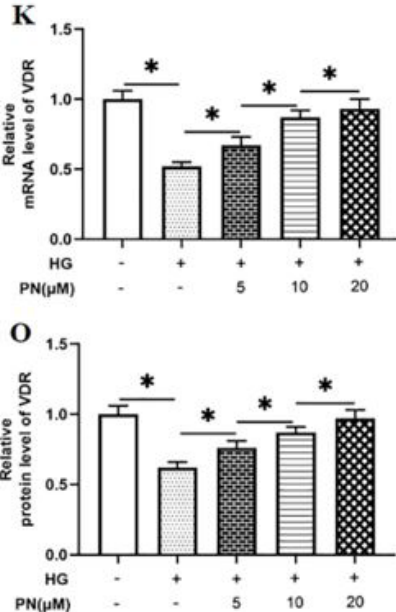
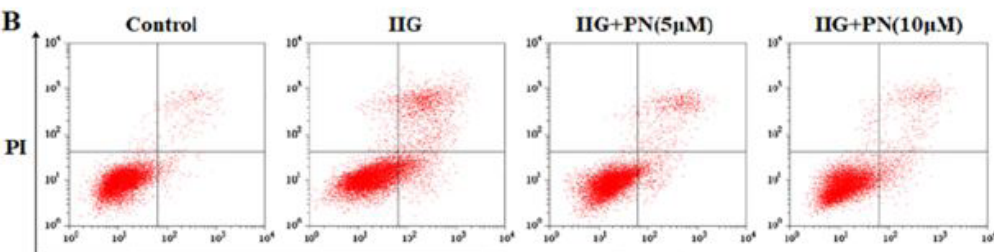

Annexin VFITC
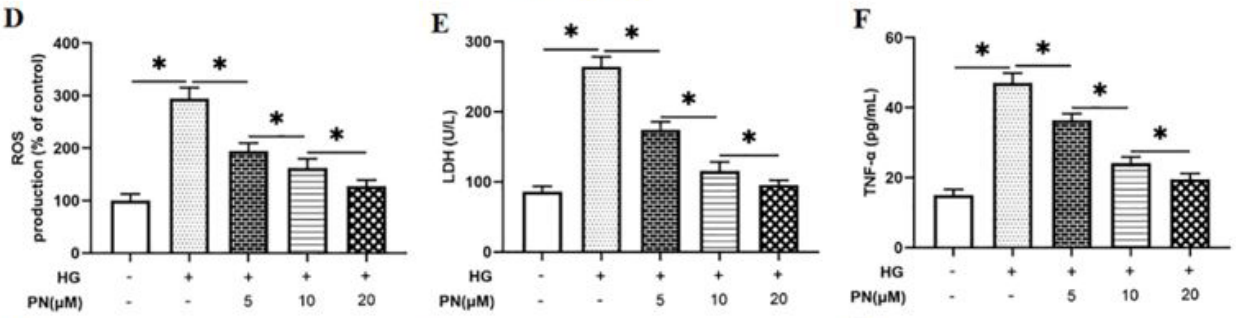

H
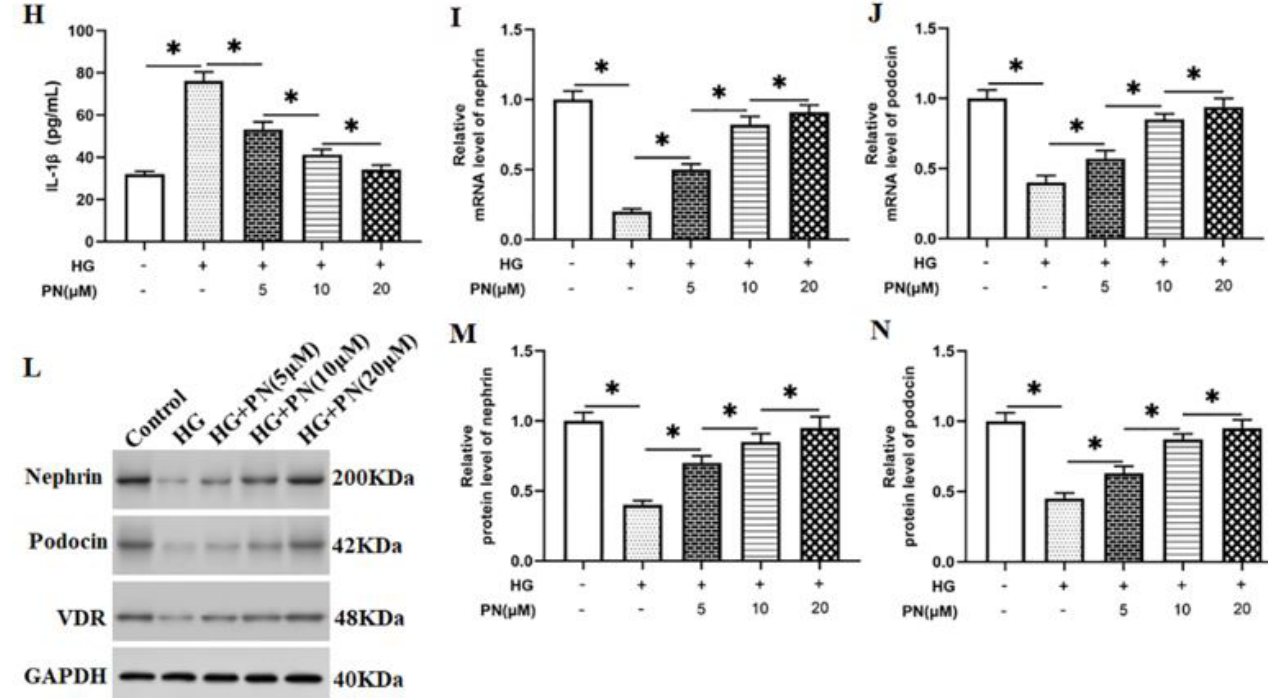

M

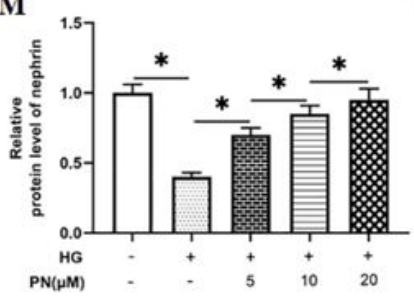

N

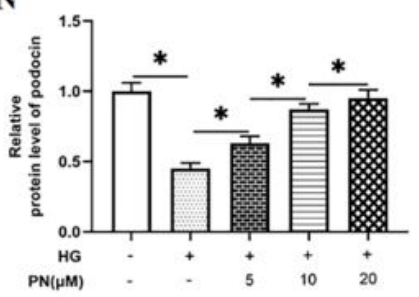

Figure 1. Parthenolide relieves MPC5 cells damage induced by high glucose. MPC5 cells were incubated with different concentrations $(5 \mu \mathrm{M}, 10$ $\mu \mathrm{M}$, and $20 \mu \mathrm{M}$ ) of parthenolide for $72 \mathrm{~h}$ after HG induction. (A) Cell viability was detected by using MTT assay. (B and C) MPC5 cell apoptosis induced by HG were detected by using flow cytometry. (D) ROS level was detected by using DCFH-DA ROS fluorescent probe. (E-H) LDH activity, the secretion of cytokines IL-6, TNF- $\alpha$ and IL- $1 \beta$ were analyzed with ELISA kits. (I-K) The levels of nephrin, podocin and VDR mRNA in MPC5 cells were examined by using RT-qPCR. (L-O) The expression levels of nephrin, podocin and VDR proteins in HG-induced MPC5 cells were analyzed by using Western botting. Statistical significance was analyzed utilizing the Student's t-test. Values were exhibited as mean \pm SEM. $\mathrm{N}=6,{ }^{\star} P<0.05$. 
PN can increase the level of VDR in MPC5 cells in HG-induced MPC5 cells, but the specific mechanism of action is unclear. In this study, we found that the expression level of DNMT1 protein was significantly increased under HG conditions, and the protein expression level of DNMT1 was significantly reduced after PN incubation. After LV-DNMT1 transfection, the expression level of DNMT1 protein increased significantly (Figure 2A and 2B), on the contrary, the expression level of VDR mRNA and protein decreased significantly (Figure 2C and 2D). Then, we used the online database MethPrimer to predict the CpG islands in the promoter region of VDR, and found that the promoter region of VDR contained $1 \mathrm{CpG}$ island (Figure 2E). Interestingly, ChIP experiment discovered that the enrichment of DNMT1 in the VDR promoter region increased under HG conditions, and the enrichment of DNMT1 in the VDR promoter region was significantly reduced after PN incubation (Figure 2F). We are eager to explore whether PN regulates the methylation level of VDR promoter region by regulating the expression of DNMT1. Therefore, we transfected MPC5 cells with LV-DNMT1. The results of MSP experiment showed that the methylation level of VDR
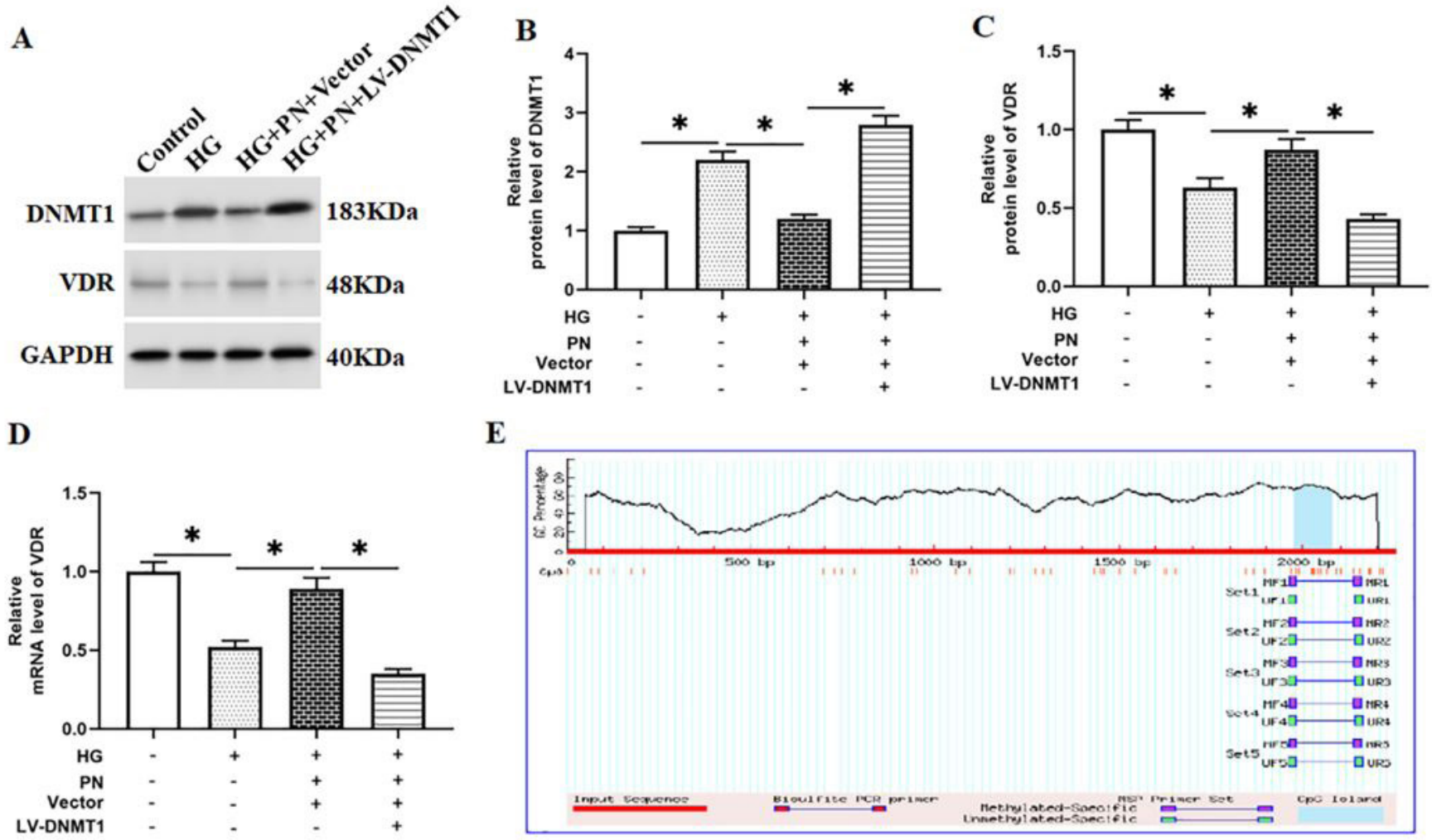

$\mathbf{E}$
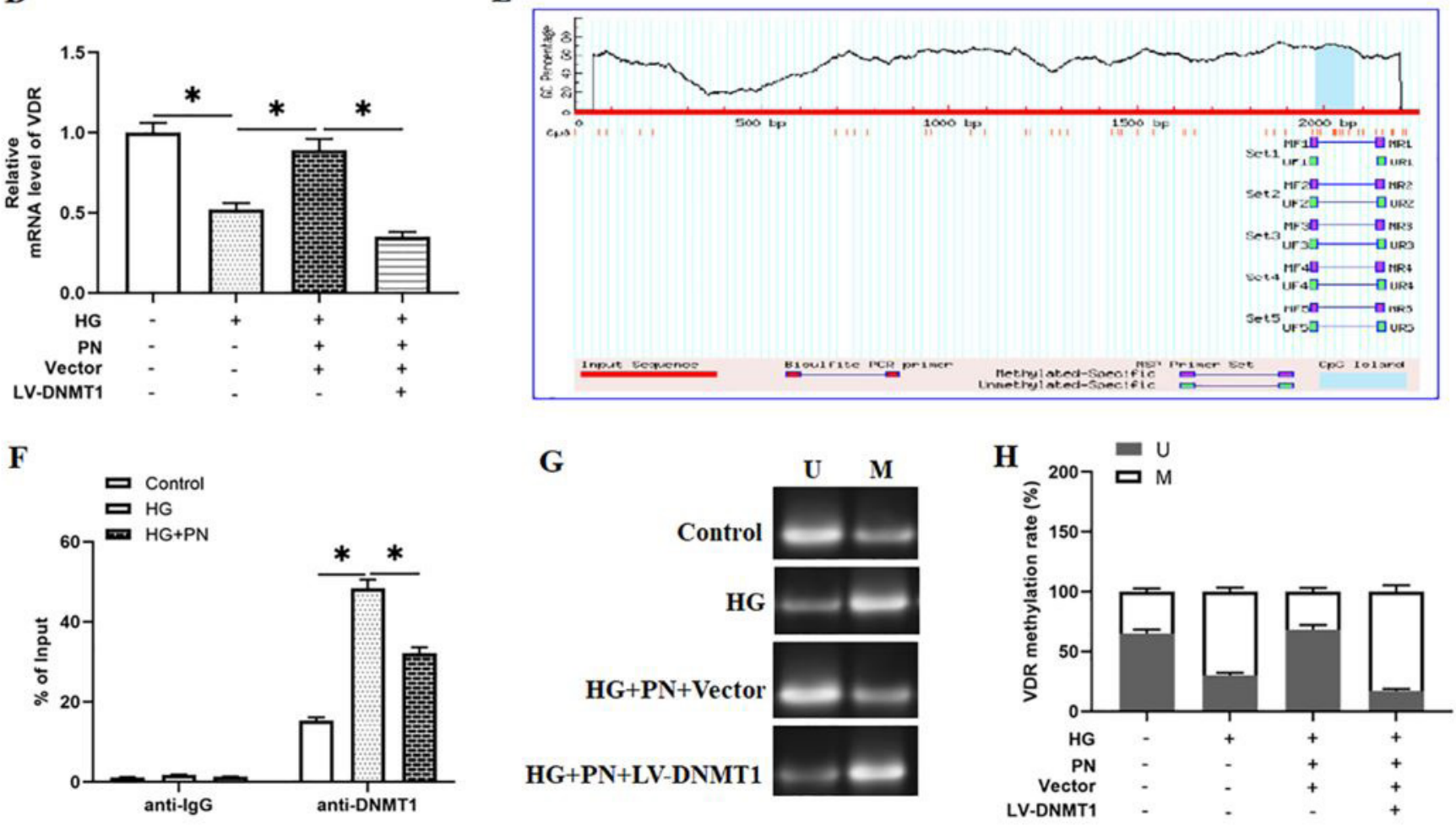

Figure 2. Parthenolide regulates DNMT1-mediated methylation of VDR promoter. HG-induced MPC5 cells were incubated with $10 \mu \mathrm{M}$ parthenolide for $72 \mathrm{~h}$ after $24 \mathrm{~h}$ pre-transfection of LV-DNMT1. (A, B and C) The expression levels of DNMT1 and VDR proteins in MPC5 cells were analyzed by using Western botting. (D) The level of VDR mRNA in MPC5 cells was examined by using RT-qPCR. (E) The online prediction software MethPrimer was used to predict the location of the CPG island in the VDR promoter region. (F) ChIP-qPCR was used to analyze the enrichment of DNMT1 in the VDR promoter region after HG and parthenolide treatment, the normal rat IgG (IgG) was used as a negative control, data represent mean values relative to input (\% Input). ( $\mathrm{G}$ and $\mathrm{H}$ ) The methylation status of VDR promoter was analyzed by using methylation-specific PCR (MSP) in MPC5 cells. M, methylation-specific primer amplification; U, unmethylation-specific amplification. Statistical significance was analyzed utilizing the Student's t-test. Values were exhibited as mean $\pm \mathrm{SEM}$. N=6, ${ }^{\star} P<0.05$. 
promoter was significantly increased in HG-induced MPC5 cells, and the methylation level of VDR promoter was significantly reduced after PN incubation, while DNMT1 overexpression reversed this phenomenon (Figure $2 \mathrm{G}$ and $2 \mathrm{H}$ ).

\subsection{Overexpression of VDR inhibits MPC5 cells damage induced by high glucose}

To further verify the effect of VDR on MPC5 cell damage induced by HG, we performed overexpression of VDR, and found that the expression levels of VDR, nephrin and podocin mRNA were significantly increased (Figure $3 \mathrm{~A}, 3 \mathrm{D}$ and $3 \mathrm{E}$ ), apoptosis was significantly reduced (Figure 3B and 3C), ROS level (Figure 3F), LDH activity and the secretion of cytokine IL-6, TNF- $\alpha$ and IL- $1 \beta$ were significantly reduced (Figure 3G-J). These results suggested that VDR upregulation could inhibit HG-induced MPC5 cell damage.

\subsection{Parthenolide regulates VDR expression to relieve MPC5 cells damage induced by high glucose}

It is reported that the increased level of VDR could prevent podocyte damage (Yang et al., 2018). In this study, we also found that the expression of VDR mRNA in MPC5 cells was significantly

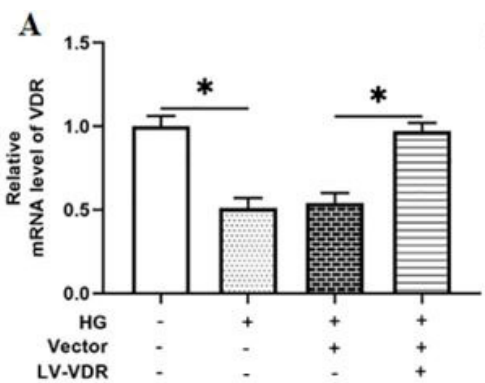

C

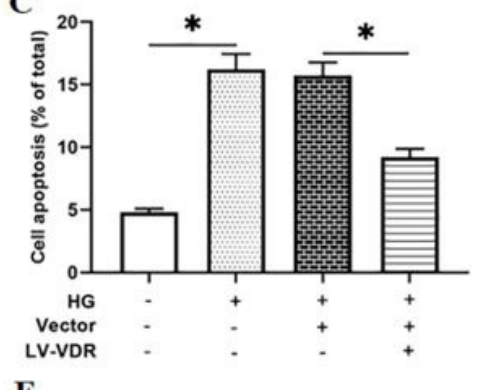

F

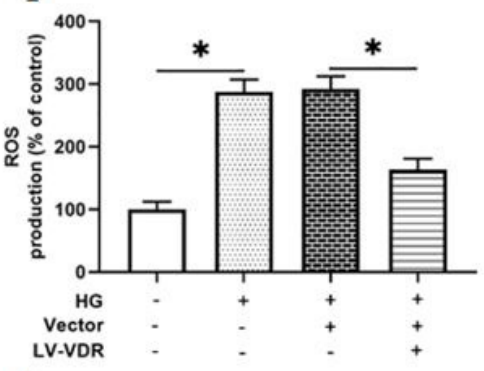

I

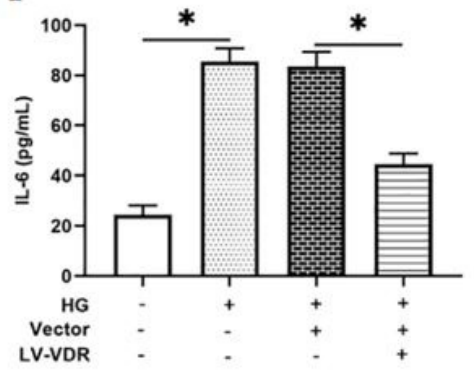

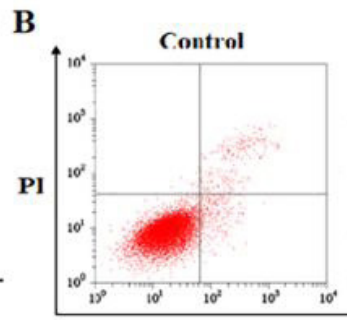
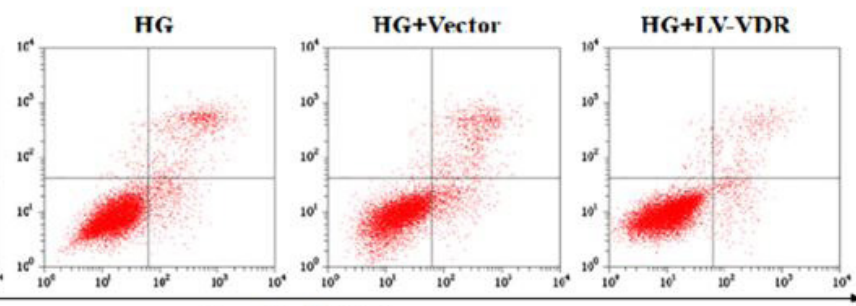

D

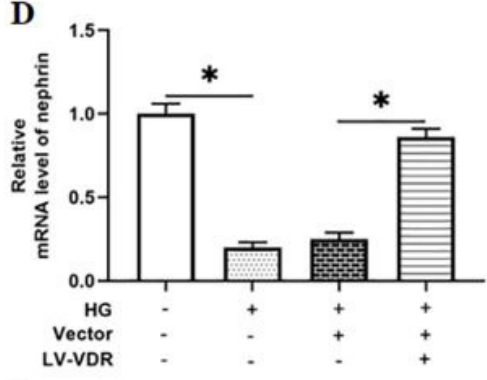

G
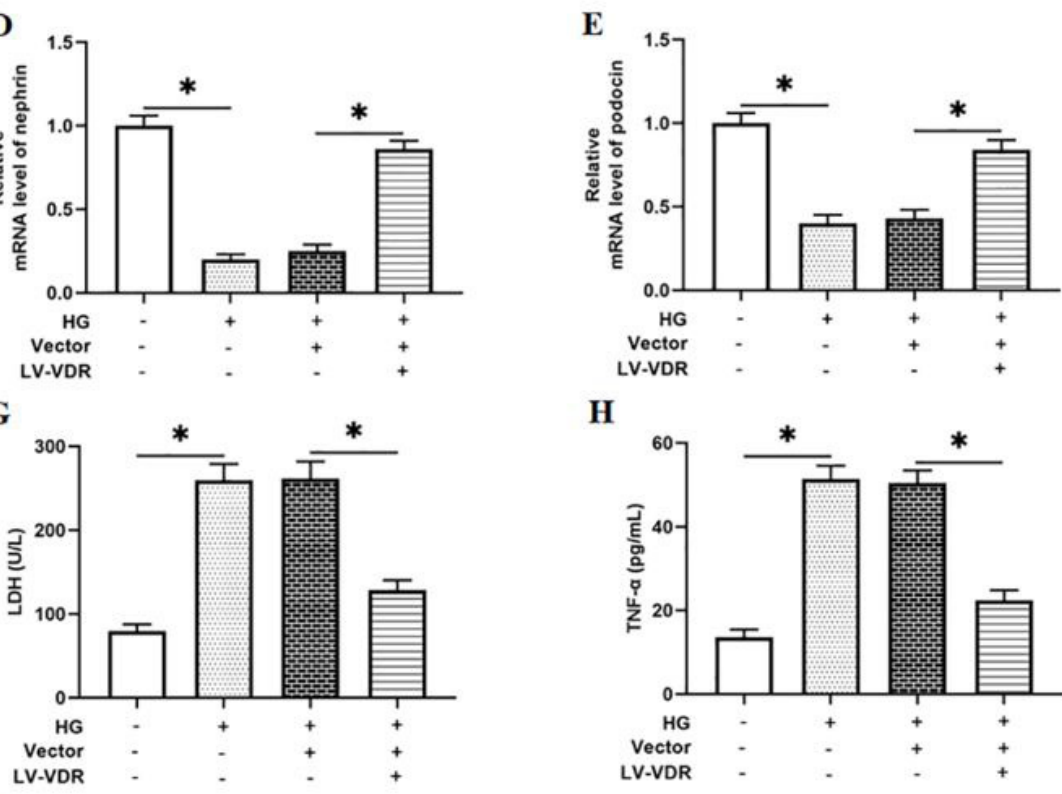

H

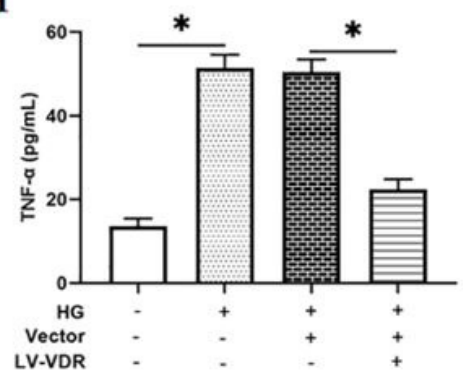

$\mathbf{J}$

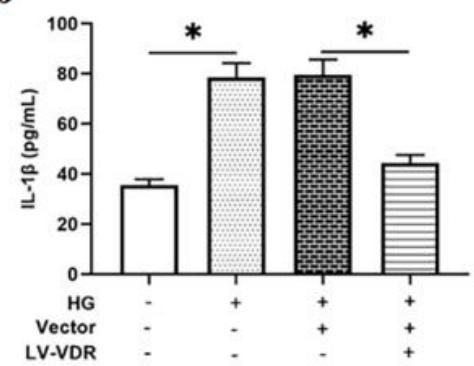

Figure 3. Overexpression of VDR inhibits MPC5 cells damage induced by high glucose. HG-induced MPC5 cells were incubated with $10 \mu \mathrm{M}$ parthenolide for $72 \mathrm{~h}$ after $24 \mathrm{~h}$ pre-transfection of LV-VDR. (A, D and E) The levels of VDR, nephrin and podocin mRNA in MPC5 cells were examined by using RT-qPCR. (B and C) MPC5 cell apoptosis was detected by using flow cytometry. (F) ROS level was detected by using DCFH-DA ROS fluorescent probe. (G-J) LDH activity, the secretion of cytokines IL-6, TNF- $\alpha$ and IL-1 $\beta$ were analyzed with ELISA kits. Statistical significance was analyzed utilizing the Student's t-test. Values were exhibited as mean \pm SEM. $N=6,{ }^{*} P<0.05$. 
reduced after HG induction. In addition, we also found that PN treatment could significantly increase the expression level of VDR mRNA (Figure 4A). Then, we interfered with VDR and found that the expression levels of VDR, nephrin and podocin mRNA were significantly reduced (Figure $4 \mathrm{~A}, 4 \mathrm{D}$ and $4 \mathrm{E}$ ), and MPC5 cell apoptosis (Figure 4B and 4C), ROS level (Figure 4F), LDH activity and the secretion of cytokines IL- 6 , TNF- $\alpha$ and IL- $1 \beta$ were significantly increased (Figure 4G-J). Taken together, these findings suggested that PN alleviates HG-induced MPC5 cell damage by increasing the level of VDR.

\subsection{Parthenolide relieves MPC5 cells damage induced by high glucose by regulating VDR to activate AKT}

According to reports, AKT activation can alleviate DN in rats (Rai et al., 2019). Our study found that both VDR

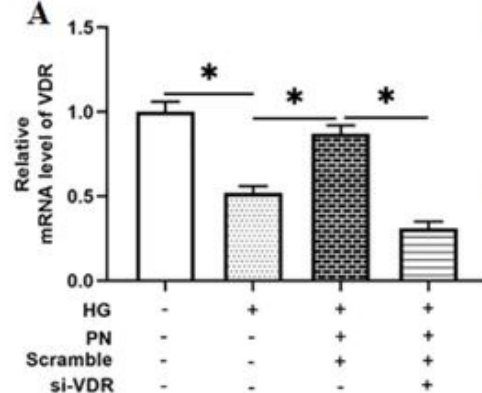

B

C

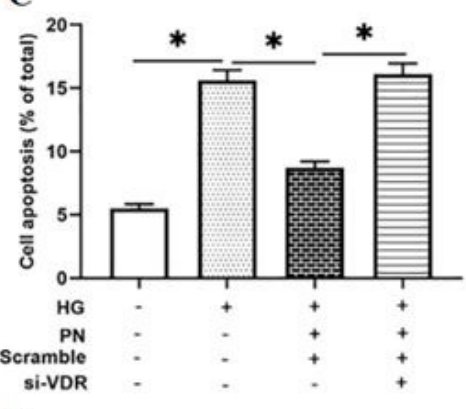

F

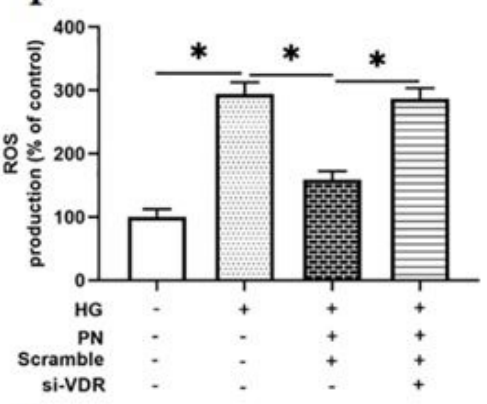

I

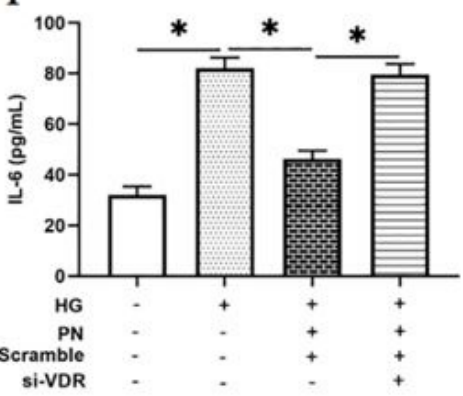

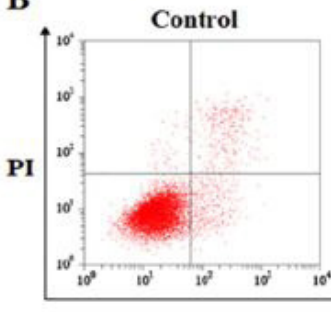
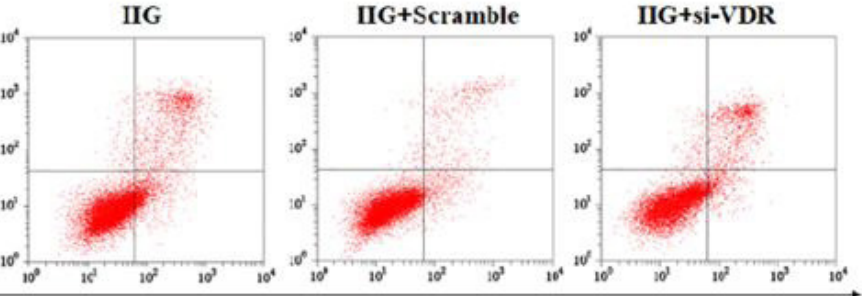

Annexin VFITC

D

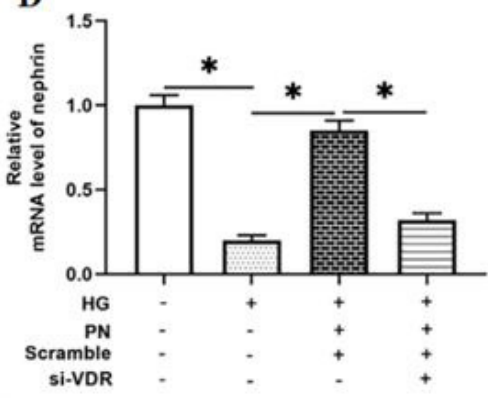

G

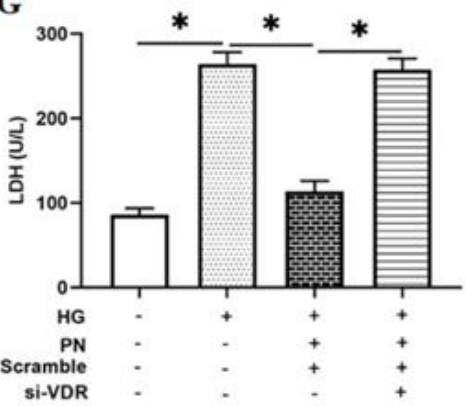

$\mathbf{J}$

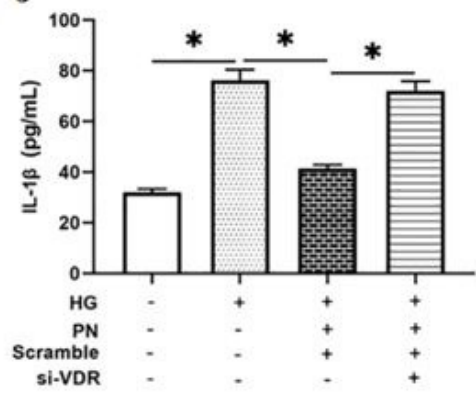

E

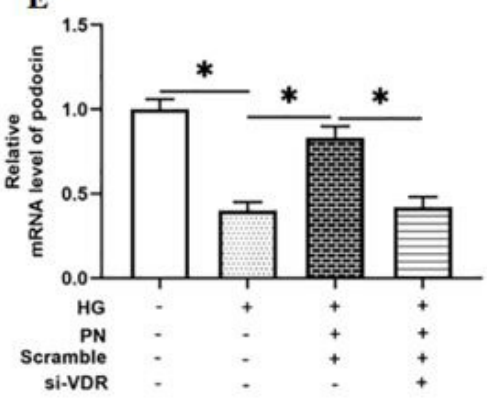

$\mathbf{H}$

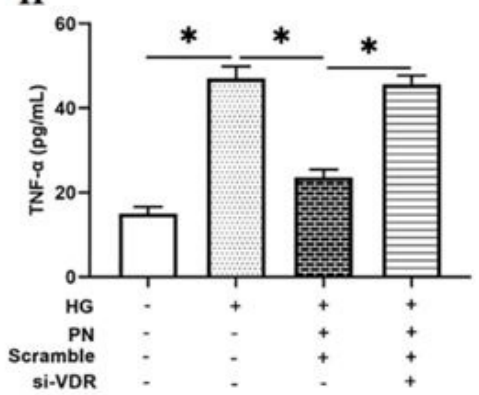

Figure 4. Parthenolide regulates VDR expression to relieve MPC5 cells damage induced by high glucose. HG-induced MPC5 cells were incubated with $10 \mu \mathrm{M}$ parthenolide for $72 \mathrm{~h}$ after $24 \mathrm{~h}$ pre-transfection of si-VDR (A, D and E) The levels of VDR, nephrin and podocin mRNA in MPC5 cells were examined by using RT-qPCR. (B and C) MPC5 cell apoptosis was detected by using flow cytometry. (F) ROS level was detected by using DCFH-DA ROS fluorescent probe. (G-J) LDH activity, the secretion of cytokines IL-6, TNF- $\alpha$ and IL-1 $\beta$ were analyzed with ELISA kits. Statistical significance was analyzed utilizing the Student's t-test. Values were exhibited as mean $\pm \mathrm{SEM}$. N=6, ${ }^{\star} P<0.05$. 
overexpression and PN treatment could promote $\mathrm{AKT}$ activation (Figure 5A-D), and the latter achieved this effect by promoting the expression of VDR, and the addition of the AKT inhibitor MK2206 reversed the effect of PN (Figure 5E and 5F), but the addition of MK2206 treatment had no effect on the expression of VDR (Figure 5G and 5H). However, after MK2206 treatment, the expression levels of nephrin and podocin proteins were significantly reduced (Figure 5G, 5I and 5J), cell apoptosis
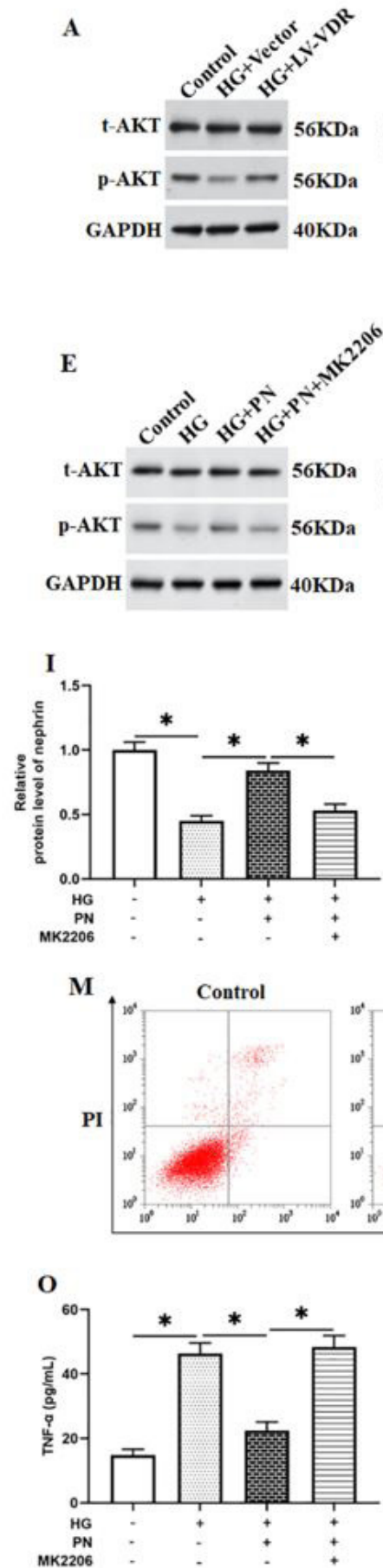

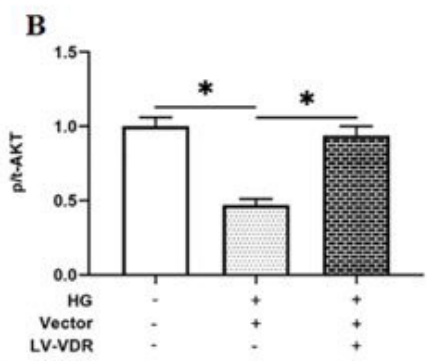

$F$
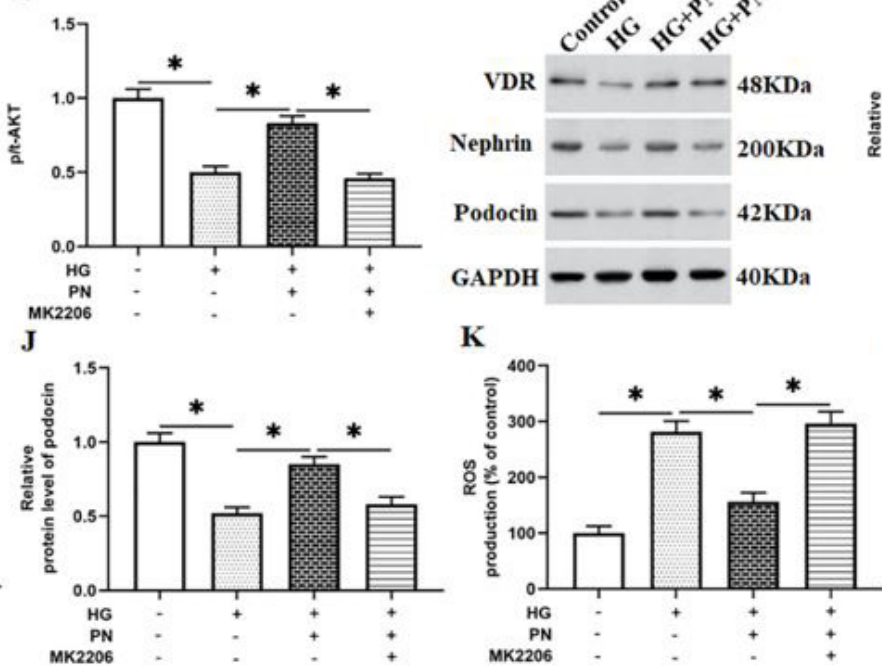

G
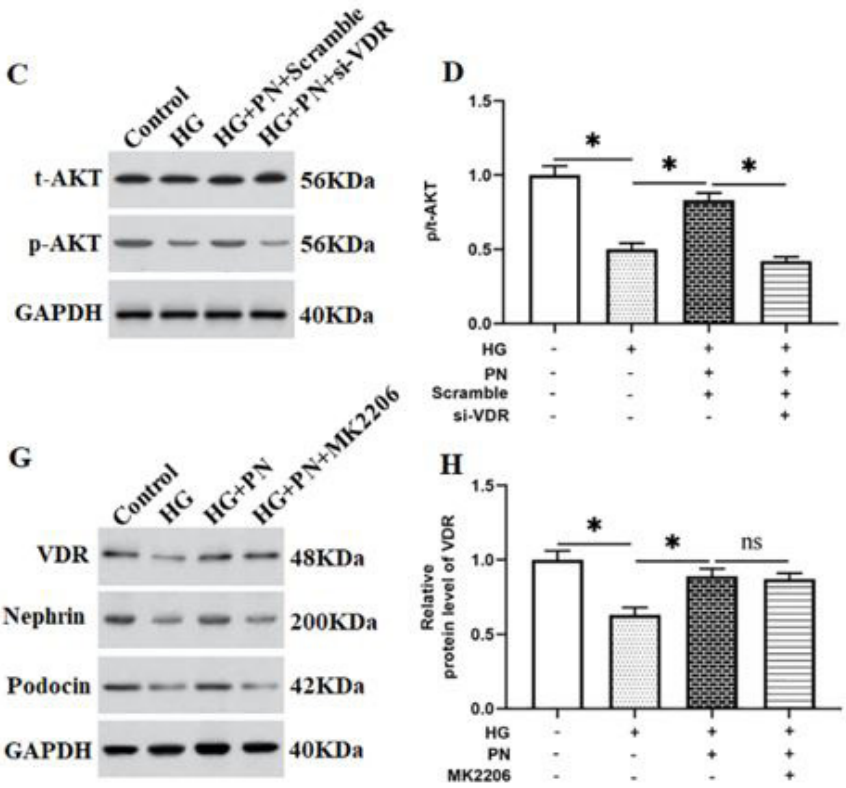

L

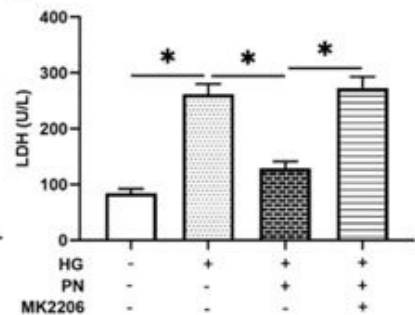

$\mathbf{N}$
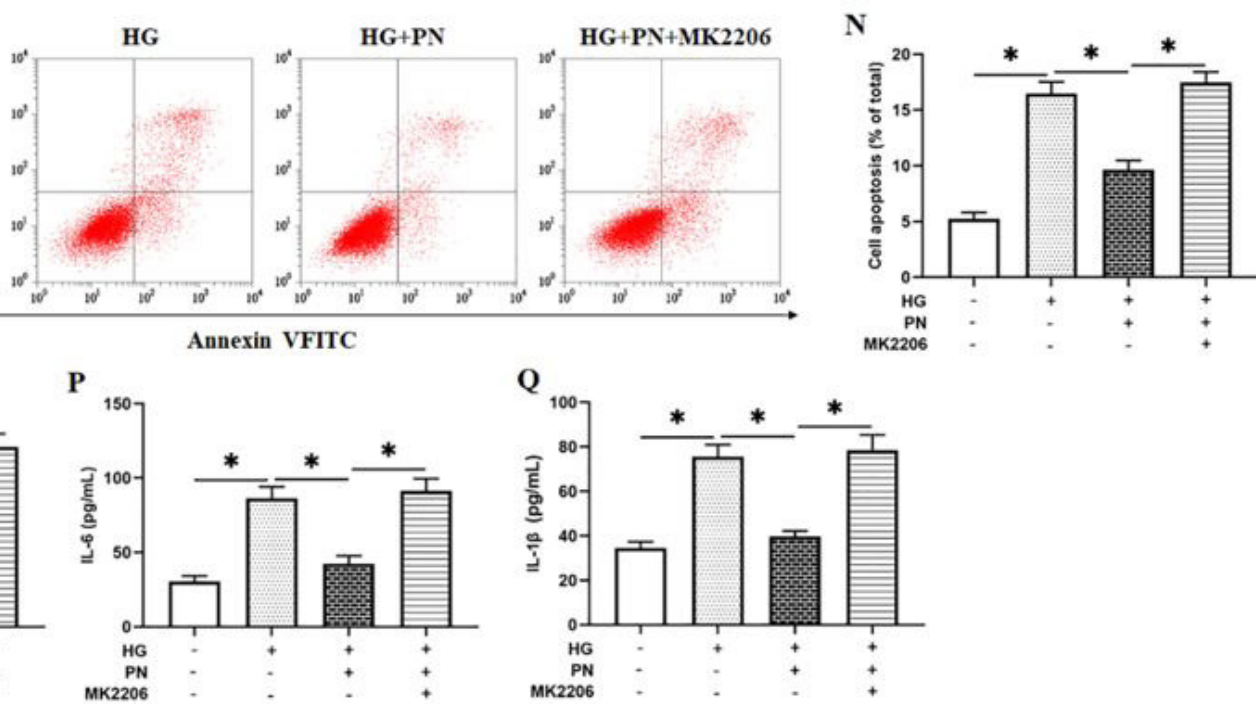

Figure 5. Parthenolide relieves MPC5 cells damage induced by high glucose by regulating VDR to activate AKT. HG-induced MPC5 cells were transfected with LV-VDR or si-VDR, as well as incubated with $10 \mu \mathrm{M}$ parthenolide for $72 \mathrm{~h}$ or together with $100 \mathrm{nM}$ MK2206 for $2 \mathrm{~h}$. (A-J) The expression levels of p-AKT, VDR, nephrin and podocin proteins in MPC5 cells were analyzed by using Western botting. (K) ROS level was detected by using DCFH-DA ROS fluorescent probe. (M and N) MPC5 cell apoptosis was detected by using flow cytometry. (L and O-Q) LDH activity, the secretion of cytokines IL- 6 , TNF- $\alpha$ and IL- $1 \beta$ were analyzed with ELISA kits. Statistical significance was analyzed utilizing the Student's t-test. Values were exhibited as mean \pm SEM. $N=6$, ${ }^{*} P<0.05$; ns $P>0.05$. 
was significantly increased (Figure $5 \mathrm{M}$ and $5 \mathrm{~N}$ ), ROS level (Figure 5K), LDH activity and the secretion of cytokines IL-6, TNF- $\alpha$ and IL- $1 \beta$ were significantly increased (Figure $5 \mathrm{~N}, 5 \mathrm{O}$ $5 \mathrm{Q})$. These results fully indicate that parthenolide activates AKT by regulating the expression of VDR to alleviate the MPC5 cells damage induced by HG.

\subsection{Parthenolide relieves STZ-induced diabetic nephropathy in mice}

The diabetic mouse model induced by streptozotocin (STZ) is a relatively common modeling method (Lin et al., 2021). In this study, we used STZ to induce mice to establish a DN mouse model. The results of HE staining showed that the control group had intact glomerular and tubular morphology, while the diabetic group had renal tubular basement membrane thickening and glomerular hypertrophy. Compared with DN mice, the kidney structure of mice was improved after PN treatment (Figure 6A). For Masson staining, the blue area of kidney tissue represents collagen, indicating fibrosis (Figure 6A, 6B). The collagen deposition in the glomerular lumen and renal tubule lumen of the DN group was 3.4 times that of the control group, but decreased to 1.5 times after PN treatment. Compared with the control group, the DN group mice urinary albumin excretion

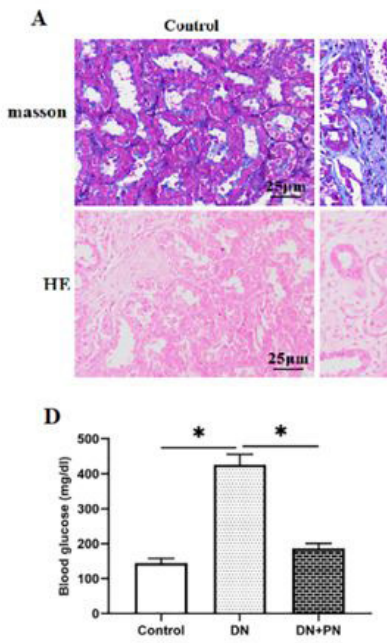

$\mathbf{H}$

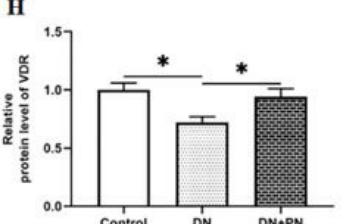

L
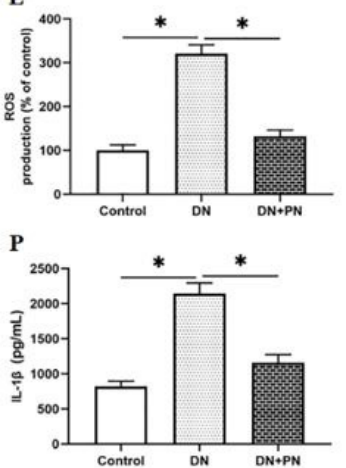

DN DN+PN
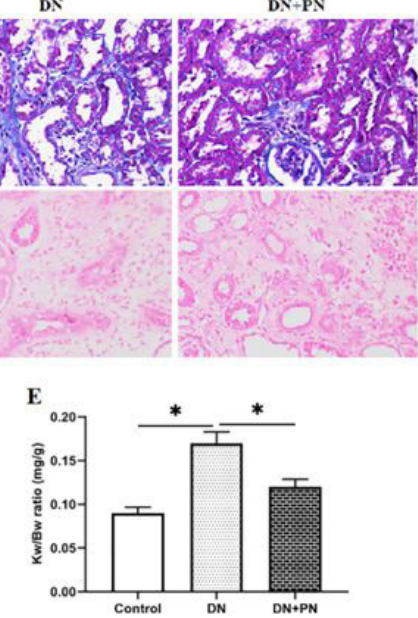

I

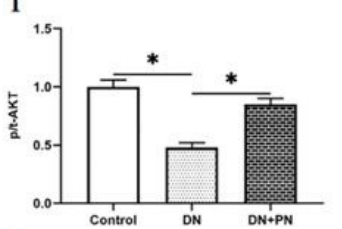

M

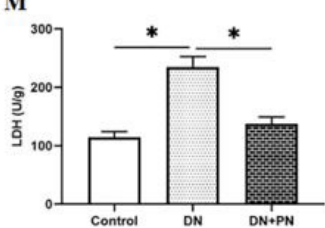

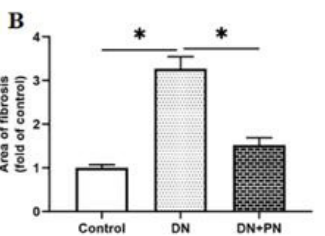

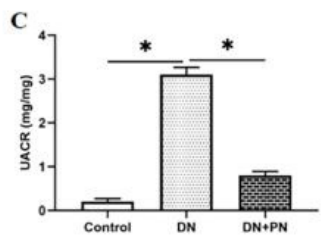

F
DNMT1 - - 183KDa
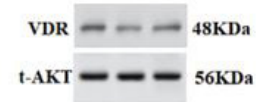

p-AKT $--156 \mathrm{KDa}$

Nephrin $---200 \mathrm{KD}$

Podocin - - 42KDa

GAPDH $---40 \mathrm{KDa}$

$\mathbf{J}$

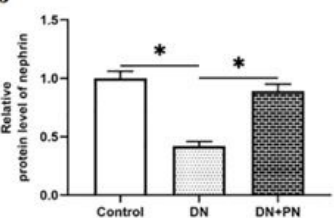

$\mathbf{N}$

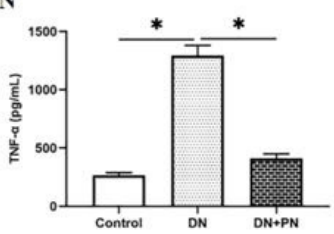

G

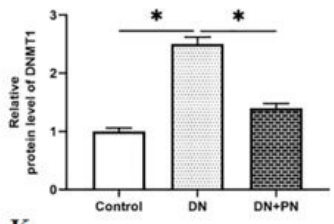

K

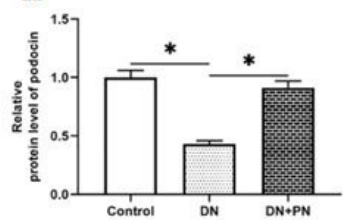

o

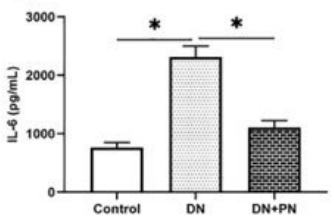

Figure 6. Parthenolide relieves STZ-induced diabetic nephropathy in mice. Male C57BL/6 mice were injected with $50 \mathrm{mg} / \mathrm{kg}$ streptozotocin (STZ) intraperitoneally continue 5 days, and fed with high-fat and high-sugar for 6 weeks to establish a mouse model of diabetic nephropathy (DN). The control group mice were injected with citrate buffer, and parthenolide treatment group mice were injected with $5 \mathrm{mg} / \mathrm{kg}$ parthenolide intraperitoneally every other day after modeling for 4 weeks. (A and B) Paraffin-embedded kidney tissues stained with HE and Masson staining were observed under light microscope $(400 \mathrm{x}$, bar $=25 \mu \mathrm{m})$, the blue area in Masson staining represents the fibrosis in kidney tissues. (C) UACR (urinary albumin-to-creatinine ratio) in different groups of mice. (D) Blood glucose of each group of mice. (E) Relative weight of mouse kidney in each group. (F-K) The expression levels of DNMT1, VDR, p-AKT, nephrin and podocin proteins in kidney tissues of mice were analyzed by using Western botting. (L) ROS level was detected by using DCFH-DA ROS fluorescent probe. (M-P) LDH activity, the secretion of cytokines IL-6, TNF- $\alpha$ and IL- $1 \beta$ were analyzed with ELISA kits. Statistical significance was analyzed utilizing the Student's t-test. Values were exhibited as mean \pm SEM. $\mathrm{N}=10,{ }^{\star} P<0.05$. 
(Figure 6C), blood sugar (Figure 6D) and relative kidney weight (Figure 6E) were significantly increased, the expression levels of VDR, p-AKT, nephrin and podocin proteins were significantly decreased (Figure 6F, 6H-K), and renal DNMT1 expression level (Figure 6F and 6G), ROS level (Figure 6L), LDH activity and the secretion of inflammatory factors IL-6, TNF- $\alpha$ and IL- $1 \beta$ were significantly increased (Figure 6M-P). Compared with the DN group, the kidney inflammation and damage of the mice in the parthenolide treatment group were significantly alleviated. Therefore, we speculate that PN has a certain therapeutic effect on diabetic nephropathy in mice.

\section{Discussion}

Early symptoms of DN include proteinuria, mesangial matrix expansion, basement membrane thickening, and podocyte damage (Keating et al., 2017). Podocytes constitute the outermost layer of the glomerular filtration barrier and are a highly differentiated cell and podocyte injury is usually used as an indicator to evaluate the progression and severity of DN (Cheng et al., 2021). Yin deficiency and heat, stagnation of qi and blood stasis are the main pathogenic factors of $\mathrm{DN}$, and traditional Chinese medicine is widely used in the treatment of $\mathrm{DN}$ due to its unique conditioning advantages (Wang et al., 2019). PN is the main active ingredient of the medicinal plant feverfew. A study showed that the glomerular mesangial expansion, glomerular hypertrophy and the albuminuria of $\mathrm{db} / \mathrm{db}$ mice are improved after treatment with PN (Hao et al., 2020). However, the treatment mechanism and stability of PN on DN are still unclear. Similarly, our study used STZ and high-sugar and high-fat diet to induce C57BL/6 mice to establish a DN mouse model, and used HG to induce MPC5 cells to establish a DN cell model, and we found that PN could significantly improve DN mouse renal tubular basement membrane thickening, glomerular hypertrophy, renal fibrosis, proteinuria excretion and blood sugar, as well PN could significantly improve HG-induced MPC5 cell apoptosis and inflammation, and PN could significantly increase the expression levels of matrix-related proteins nephrin and podocin in mouse kidneys and MPC5 cells.

It is reported that the progression of diabetes may be related to gene methylation modification (Bansal \& Pinney, 2017). A study identified 703 autosomal differentially methylated sites (515 hypermethylated sites and 188 hypomethylated sites) by sequencing HIV-infected podocytes, among them, hypermethylation genes regulate important features of podocyte function, including vesicle-mediated transport, extracellular secretion and lipid transport, and hypomethylation genes regulate the progression of HIV-related nephropathy, including cell cycle, division, transcription regulation and DNA repair (Li et al., 2018). DNMT1 is one of the key enzymes involved in methylation modification. A study found that in type 2 diabetic mice and HG-induced podocytes, the level of DNMT1 is significantly increased. After treatment with the methylation inhibitor 5-Aza, the level of DNMT1 is significantly reduced, and mouse total cholesterol, triglycerides, low-density lipoprotein levels and urinary albumin excretion are significantly reduced (Zhang et al., 2017). As well, a related study claimed that depletion or inhibition of DNMT1 could block the accumulation of ROS in HG-treated renal tubular epithelial cells (Zeng et al., 2018). Therefore, inhibiting the expression of DNMT1 may become a new direction for the treatment of DN. According to a report, $\mathrm{PN}$ could reduce the expression level of DNMT1 in leukemia cell lines in a dose-dependent manner, and the sequencing results found that PN could reduce the overall DNA methylation level in both xenograft mice and leukemia cell lines, indicating that $\mathrm{PN}$ is effective DNA methylation inhibitor (Liu et al., 2009). However, the inhibitory function of PN on DNMT1 has not been reported in DN. Consistent with previous studies, we found that DNMT1 was upregulated in DN mice and HG-induced MPC5 cells, and PN treatment could significantly reduce the expression level of DNMT1.

More and more studies have reported the protective effect of VDR on the kidney (Yang et al., 2018), and the upregulation of VDR could alleviate the symptoms of DN mice and HG-induced podocyte damage (Lei et al., 2020). In pediatric tuberculosis, VDR hypermethylation is significantly correlated with lower vitamin D levels and lower VDR gene expression levels, and this reverse correlation may be involved in the damage of antibacterial effector cell responses (Maruthai et al., 2020). Merely, the methylation level of VDR has not been reported in DN. A study showed that the level of DNMT1 is significantly upregulated in HIV-infected podocytes, and the CpG methylation of the VDR promoter is increased, while the expression of VDR is significantly down-regulated. DNMT1 may be involved in regulating the methylation level of the VDR promoter (Nirupama Chandel \& Lan, 2015). Our research is consistent with this. We found that in HG-induced podocytes, the expression of VDR protein was significantly reduced, while the methylation level of the promoter was significantly increased. Overexpression of DNMT1 could promote the methylation level of the VDR promoter. Surprisingly, we found that PN could promote the expression of VDR protein and inhibit the methylation level of VDR promoter. Simultaneously, a research reported that up-regulation of VDR could activate AKT signaling to reduce HG-induced oxidative stress and apoptosis of renal tubular epithelial cells (Zhu et al., 2019). Our study found that VDR overexpression could promote the phosphorylation level of AKT in podocytes induced by HG, and PN could promote the phosphorylation level of AKT death by promoting the expression of VDR, and the addition of AKT inhibitor MK2206 reversed the effect of PN.

In summary, this study evaluated the therapeutic effect of $\mathrm{PN}$ on DN from in vivo and in vitro levels, and we found that PN inhibits DNMT1 in DN, and PN promotes AKT phosphorylation by regulating DNMT1-mediated VDR methylation, which provides a new direction for the research of clinical new drugs and the discovery of therapeutic targets for diabetes.

\section{Abbreviations}

Dulbecco's Modified Eagle Medium (DMEM), phosphate buffered saline (PBS), Ethylene Diamine Tetraacetic Acid (EDTA), Fetal Bovine Serum (FBS), Diabetic nephropathy (DN), type 2 diabetes (T2DM), DNA methyltransferase 1 (DNMT1), high glucose (HG), Vitamin D Receptor (VDR), parthenolide (PN), streptozotocin (STZ), reactive oxygen species (ROS). 


\section{Ethics approval and consent to participate}

All patients gave informed consent and signed an informed consent form. All samples obtained in this study were approved by the ethics committee of the Xian Hospital of Traditional Chinese Medicine and abided by the ethical guidelines of the Declaration of Helsinki. All animal experiments comply with the guidelines for the care and use of laboratory animals established by the National Institutes of Health (Bethesda, Maryland, USA).

\section{Conflict of interest}

The authors declare that they have no conflict of interest.

\section{Availability of data and materials}

All the data and materials are available.

\section{Author contributions}

Xinbo Yang designed the study. Xinbo Yang wrote the manuscript. Yulei Zhang and Ni Yang performed the experiments. Xiao Yu and Xin Gao collected and analyzed data. Meiyun Zhao revised and proofread the manuscript.

\section{References}

Ahmad, A., Amir, R.M., Ameer, K., Ali, S.W., Siddique, F., Hayat, I., Ahmad, Z., \& Faiz, F. (2020). Ameliorative effects of fenugreek (Trigonella foenum-graecum) seed on type 2 diabetes. Food Science and Technology (Campinas), 41, 349-354. http://dx.doi.org/10.1590/ fst. 03520

Bansal, A., \& Pinney, S. E. (2017). DNA methylation and its role in the pathogenesis of diabetes. Pediatric Diabetes, 18(3), 167-177. http:// dx.doi.org/10.1111/pedi.12521. PMid:28401680.

Cheng, Q., Pan, J., Zhou, Z. L., Yin, F., Xie, H. Y., Chen, P. P., Li, J. Y., Zheng, P. Q., Zhou, L., Zhang, W., Liu, J., \& Lu, L. M. (2021). Caspase-11/4 and gasdermin D-mediated pyroptosis contributes to podocyte injury in mouse diabetic nephropathy. Acta Pharmacologica Sinica, 42(6), 954-963. http://dx.doi.org/10.1038/s41401-020-00525-z. PMid:32968210.

Cho N.H., Shaw J.E., Karuranga S., Huang Y., da Rocha Fernandes, J.D., Ohlrogge, A.W., \& Malanda, B. (2018). IDF Diabetes Atlas: global estimates of diabetes prevalence for 2017 and projections for 2045. Diabetes Research \& Clinical Practice, 138, 271-281. http://dx.doi. org/10.1016/j.diabres.2018.02.023.

Freund, R. R. A., Gobrecht, P., Fischer, D., \& Arndt, H. D. (2020). Advances in chemistry and bioactivity of parthenolide. Natural Product Reports, 37(4), 541-565. http://dx.doi.org/10.1039/C9NP00049F. PMid:31763637.

Hao, Q., Wang, B. B., Zhang, W., Qiu, W., Liu, Q. L., \& Li, X. M. (2020). NF-kb inhibitor parthenolide promotes renal tubules albumin uptake in Type 2 diabetic nephropathy. Chinese Medical Sciences Journal, 35(1), 31-42. http://dx.doi.org/10.24920/003573. PMid:32299536.

Jiang, C., Zhu, J., Liu, Y., Luan, X., Jiang, Y., Jiang, G., \& Fan, J. (2017). The methylation state of VDR gene in pulmonary tuberculosis patients. Journal of Thoracic Disease, 9(11), 4353-4357. http://dx.doi. org/10.21037/jtd.2017.09.107. PMid:29268504.

Jones, P. A. (2012). Functions of DNA methylation: islands, start sites, gene bodies and beyond. Nature Reviews. Genetics, 13(7), 484-492. http://dx.doi.org/10.1038/nrg3230. PMid:22641018.
Keating, S. T., Van Diepen, J. A., Riksen, N. P., \& El-Osta, A. (2017). Epigenetics in diabetic nephropathy, immunity and metabolism. Diabetologia, 61(1), 6-20. http://dx.doi.org/10.1007/s00125-0174490-1. PMid:29128937.

Lei, M., Liu, Z., \& Guo, J. (2020). The emerging role of vitamin D and vitamin D receptor in diabetic nephropathy. BioMed Research International, 2020(9), 1-8. https://doi.org/10.1155/2020/4137268.

Li, H., Zhang, W., Zhong, F., Das, G. C., Xie, Y., Li, Z., Cai, W., Jiang, G., Choi, J., Sidani, M., Hyink, D. P., Lee, K., Klotman, P. E., \& He, J. C. (2018). Epigenetic regulation of RCAN1 expression in kidney disease and its role in podocyte injury. Kidney International, 94(6), 11601176. http://dx.doi.org/10.1016/j.kint.2018.07.023. PMid:30366682.

Lin, H., Li, S., Zhang, J., Lin, S., Tan, B. K., \& Hu, J. (2021). Functional food ingredients for control of gestational diabetes mellitus: a review. Food Science and Technology (Campinas). In press. http://dx.doi. $\operatorname{org} / 10.1590 /$ fst.03621.

Liu, Z., Liu, S., Xie, Z., Pavlovicz, R. E., Wu, J., Chen, P., Aimiuwu, J., Pang, J., Bhasin, D., Neviani, P., Fuchs, J. R., Plass, C., Li, P. K., Li, C., Huang, T. H., Wu, L. C., Rush, L., Wang, H., Perrotti, D., Marcucci, G., \& Chan, K. K. (2009). Modulation of DNA methylation by a sesquiterpene lactone parthenolide. The Journal of Pharmacology and Experimental Therapeutics, 329(2), 505-514. http://dx.doi. org/10.1124/jpet.108.147934. PMid:19201992.

Maruthai, K., Sankar S., \& Subramanian M. (2020). Methylation status of VDR gene and its association with vitamin D status and VDR gene expression in pediatric tuberculosis disease. Immunological Investigations, 26, 1-16. http://dx.doi.org/10.1080/08820139.2020 .1810702 .

Nirupama Chandel, K. S. A., \& Lan, X. (2015). Epigenetic modulation of human podocyte vitamin D receptor in HIV Milieu. Journal of Molecular Biology, 427(20), 3201-3215. http://dx.doi.org/10.1016/j. jmb.2015.07.011. PMid:26210663.

Palomer, X., González-Clemente, J. M., Blanco-Vaca, F., \& Mauricio, D. (2008). Role of vitamin D in the pathogenesis of Type 2 Diabetes Mellitus. Diabetes, Obesity \& Metabolism, 10(3), 185-197. http:// dx.doi.org/10.1111/j.1463-1326.2007.00710.x. PMid:18269634.

Ponsonby, A. L., Cameron, F., Saffery, R., Pezic, A., Wong, N., Craig, J., Ellis, J., \& Dwyer, T. (2009). A case-sibling assessment of the association between skin pigmentation and other vitamin D-related factors and Type 1 Diabetes Mellitus. Photochemistry and Photobiology, 85(5), 1267-1270. http://dx.doi.org/10.1111/j.1751-1097.2009.00563.x. PMid:19453387.

Rai, U., Kosuru, R., Prakash, S., Tiwari, V.,\& Singh, S. (2019). Tetramethylpyrazine alleviates diabetic nephropathy through the activation of Akt signalling pathway in rats. European Journal of Pharmacology, 865, 172763. http://dx.doi.org/10.1016/j. ejphar.2019.172763.

Ritz, E., Rychlík, I., Locatelli, F., \& Halimi, S. (1999). End-stage renal failure in type 2 diabetes: a medical catastrophe of worldwide dimensions. American Journal of Kidney Diseases, 34(5), 795-808. http://dx.doi.org/10.1016/S0272-6386(99)70035-1. PMid:10561134.

Wang, D., Zhang, Z., Zekun, S. I., \& Wang, L. (2021). Circ 0006282/miR155 reduced inflammation in diabetic nephropathy via expression of SIRT1/NLRP3 signaling pathway. Food Science and Technology (Campinas). In press. http://dx.doi.org/10.1590/fst.39520.

Wang, L., Wang, Y. H., Zhang, X. H., Yang, X. L., Wei, H. L., An, Z. C., Yu, B. R., Du, D. Q., Guo, Y., \& Liu, H. F. (2019). Effectiveness comparisons of traditional Chinese medicine on treating diabetic nephropathy proteinuria: a systematic review and meta-analysis. Medicine, 98(43), e17495. http://dx.doi.org/10.1097/MD.0000000000017495. PMid:31651852. 
Wanner, N., \& Bechtel-Walz, W. (2017). Epigenetics of kidney disease. Cell and Tissue Research, 369(1), 75-92. http://dx.doi.org/10.1007/ s00441-017-2588-x. PMid:28286899.

World Health Organization - WHO. (2015). EN DG speech: WHO Director-General address the Executive Board. Geneva: WHO.

Yang, S., Li, A., Wang, J., Liu, J., Han, Y., Zhang, W., Li, Y. C., \& Zhang, H. (2018). Vitamin D receptor: a novel therapeutic target for kidney diseases. Current Medicinal Chemistry, 25(27), 3256-3271. http:// dx.doi.org/10.2174/0929867325666180214122352. PMid:29446731.

Zhen, L., Guilhem, F., Victor, G. R. (2020). Meeting the Challenge of Diabetes in China. Int J Health Policy Manag, 9(2), 47-52. http:// dx.doi.org/10.15171/ijhpm.2019.80. PMid:32124588

Zeng, S., Wu, X., Chen, X., Xu, H., Zhang, T., \& Xu, Y. (2018). Hypermethylated in cancer 1 (HIC1) mediates high glucose induced
ROS accumulation in renal tubular epithelial cells by epigenetically repressing SIRT1 transcription. Biochimica et Biophysica Acta. Gene Regulatory Mechanisms, 1861(10), 917-927. http://dx.doi. org/10.1016/j.bbagrm.2018.08.002. PMid:30496037.

Zhang, L., Zhang, Q., Liu, S., Chen, Y., Li, R., Lin, T., Yu, C., Zhang, H., Huang, Z., Zhao, X., Tan, X., Li, Z., Ye, Z., Ma, J., Zhang, B., Wang, W., Shi, W., \& Liang, X. (2017). DNA methyltransferase 1 may be a therapy target for attenuating diabetic nephropathy and podocyte injury. Kidney International, 92(1), 140-153. http://dx.doi. org/10.1016/j.kint.2017.01.010. PMid:28318634.

Zhu, X., Wu, S. H., \& Guo, H. C. (2019). Active vitamin D and vitamin $\mathrm{d}$ receptor help prevent high glucose induced oxidative stress of renal tubular cells via AKT/UCP2 signaling pathway. BioMed Research International, 2019, 9013904. http://dx.doi.org/10.1155/2019/9013904. PMid:31275989. 